\title{
Villa Voortman: Carte blanche or not?
}

Stijn Vandevelde, Jessica De Maeyer, Clara De Ruysscher, Dirk Bryssinck, Dirk Meesen, Johan Vanderstraeten \& Eric Broekaert

Accepted for publication in 'Therapeutic Communities' (13/11/2014)

\section{Introduction}

Under the impetus of the Second World War, revolutionary changes occurred in psychiatry throughout the United Kingdom during the 1940s and 1950s (Broekaert et al., 2000; Harrison \& Clark, 1992; Jones, 1968; Kennard, 1998). This led to the development of the first generation of therapeutic communities (TCs), which were - originally - primarily influenced by psychoanalytical thinking. Well-known examples are the communities developed during the Northfield experiments by Harold Bridger, amongst others, who was supervised and trained by Paula Heimann, Melanie Klein and John Rickman (Hayes, 2013) and the experimental units in Mill Hill and Dartford pioneered by Maxwell Jones, who was psychoanalytically trained and supervised by Paula Heimann and Melanie Klein (Harrison \& Clark, 1992; Hinshelwood, 1991; Jones, 1968). Although Jones was always ambivalent towards psychoanalysis, he indicated in an interview with Kari Murto at the end of his life that he had learnt a lot from psychoanalysis (personal communication Kari Murto, 1999, in Vandevelde \& Broekaert, 2009). The therapeutic communities 'avant la lettre' reacted against the existing hierarchy in the traditional psychiatric hospitals and strove for equal communication and democracy (Jones, 1968). Yet, these TC's and the first successors (such as Henderson Hospital and Dingleton somewhat later) were still located in large residential institutions.

During the 1960s, a wave of criticism rose against large hospitals, which were identified as "total institutions/asylums" (Goffman, 1961). This resulted in the deinstitutionalisation movement, a tendency which can still be recognized in present time and which went hand in hand with the upcoming anti-psychiatric movement and its important proponents such as Ronald Laing, David Cooper, Thomas Szasz and Franco Basaglia (see e.g. Crossley 1998).

Basaglia argued for the closure of psychiatric hospitals in Italy and promoted community mental health services (Davidson et al., 2010). 
"When we began our reform process, in reality we violated society by forcing it to accept the "crazy" person, and this created major problems that did not exist before. The important thing, however, even as we violated society we were there (as new "technicians") to accept the consequences of this violence, and to take responsibility for our actions in order to help the community understand what the presence of a mentally ill person in society meant."

(Basaglia, Conversations on Law 180, 1979, cf. Davidson et al., 2010)

These ideas were underpinned by existentialism of the French philosopher Sartre. Also in France, radical thinkers who aimed at reforming the way people should be treated, included Lacan ("le retour à Freud") and the postmodernist Foucault and his social critical position (Foucault, 1965).

During the 1960s, in the United States, the hippie movement and alternative lifestyles were promoted which led to the second generation of therapeutic communities (Broekaert et al., 2006). These TC's were developed to counter the uprising drug cultures and pled for total abstinence (De Leon, 2000). In analogy with existentialism in France, the human potential movement and the humanistic psychology in the United States came to their peak in the 1970s and proved to be a fertile soil for deinstitutionalisation and community mental health developments. Important proponents included Abraham Maslow, Carl Rogers, Viktor Frank1 and Fritz Perls (Friedman, 1976).

Both TC-traditions have long been thought of as quite different or even opposite, which was illustrated by how they were typically called: "democratic" (first generation) vs. "hierarchical" (second generation) (Broekaert et al. 2000). Under the impetus of Maxwell Jones, a first attempt was made to seek for convergence between both traditions, which has been realized in several places now, such as Greece (KETHEA) (Jones, 1984).

In Belgium, the first TCs originated in the beginning of the 1970s. De Sleutel ("The Key") grew out of the Youth Advise Centre (JAC) and the InfoYouthCentres. It started as a place where persons with psychiatric problems lived together on a farm in Mendonk. and opted in the beginning for an anti-psychiatric and Maxwell-Jones-inspired approach. TC De Kiem developed as a ward on the psychiatric clinic 'The Pelgrim' and functioned in accordance with the American TC principles. Gradually, De Kiem evolved towards an independent entity outside the psychiatric hospital. After De Sleutel and De Kiem, other therapeutic communities followed, such as De Spiegel and Katharsis (Broekaert et al., 2006). 
Starting in the 1990s, a remarkable initiative was built out in the Psychiatric Centres Sleidinge (close to Ghent, Belgium), where a democratic therapeutic community for dually diagnosed clients - persons with substance abuse problems and psychiatric problems (in this case mostly psychosis) - was developed, based on the ideas of Maxwell Jones and Jacques Lacan (Bryssinck et al., 2005). Influenced by the current evolutions in Belgian mental health care towards deinstitutionalisation and more community-based support, this initiative has moved to the community in Ghent, where a meeting house, called 'Villa Voortman', is located in the premises of a former textile industry manager. It's theoretical backbone is shaped by the integrative application of therapeutic community principles and psychoanalytical Lacanian thinking.

This article aims at investigating the particular position of Villa Voortman in the treatment and care continuum for dually diagnosed clients. Two research questions will be addressed:

(1). How does the combining of TC-principles and psychoanalytical ideas operate at Villa Voortman?

(2). How do the clients perceive Villa Voortman in terms of positive and negative factors?

The first question will be tackled by means of a personal account in which the developers of Villa Voortman reflect on the context, the population, the organization and principles, and the treatment contours of Villa Voortman. The second question will be addressed by means of a qualitative study using video-material of visitors' personal accounts. In the discussion, these perspectives will be compared and integrated in order to elicit current strengths of and future challenges for Villa Voortman.

\section{Research question 1: Villa Voortman: description and reflections}

\section{Villa Voortman}

Individuals with mental health issues, who have - throughout history - always searched for 'asylum', are experiencing increasing difficulties in entering treatment and care in today's rapidly changing society. They are often labeled as "treatment resistant" and are abandoned because of not being "cooperative". In some cases, they have given up upon themselves and they refuse any treatment instigated precisely as a result of their psychiatric problems. About ten years ago, a special unit for dual diagnosis was developed in order to care for these clients 
(Bryssinck et al., 2005). Under the impetus of government policy characterized by objective criteria for quality and a demand for measurable effectiveness and efficiency, this unit has been forced to narrow its focus. It has evolved towards an initiative for a younger population with a more acute profile, but with less arduous life circumstances and therefore a more favorable prognosis. The clients for which the unit originally was developed had to look again - for their own place. The societal and governmental demand for a more outlined profile of residential care is closely linked with the recent tendency in mental health care to build out community-based treatment services and to promote the integration of persons with psychological problems in society. In Dutch, we speak of 'vermaatschappelijking', by which we mean that psychiatric treatment is moved from within the institution towards society, e.g. by means of providing outreach and assertive community treatment initiatives in the clients' natural environment. The goal is inclusive citizenship, an empowering practice, based on full societal contribution of all people and with 'belonging' as a core feature (Lister, 2007; Ware et al., 2007). Perron and colleagues (2010, p.102) have called this the 'citizen experience', which is produced through individual and community participation, choice, inclusion, protection, power, voice, expression and freedom. In august 2011, Villa Voortman opened his doors for the first time, trying to create (literally as well as figuratively) a space for these individuals within a new societal reality, in order to enable them to become inclusive citizens'.

Villa Voortman focuses on persons with a dual diagnosis (substance abuse disorders combined with a psychiatric disorder, mostly psychosis) that are not connected anymore to treatment or care, due to a variety of reasons. The visitors (as they are called in Villa Voortman) have serious problems in different areas, such as a lack of social ability to live an independent life, poor living conditions and/or homelessness, judicial problems, stigmatization, financial difficulties and physical deterioration. They have no or very limited networks and they cannot fall back on family or friends. Inclusion criteria for entering Villa Voortman are limited in order to safeguard the low threshold: (1) having a dual diagnosis; and (2) being 18 years of age or older. When a new visitor arrives, an intake is carried out by the psychologist. Once someone is registered as a visitor, he or she can freely attend the meetings and/or other activities. There is no obligation to be present and people are free to come and go as they please. 
An important starting point is recognizing that most of the visitors have been excluded from society on all levels. This means that they are abandoned by society as a 'group' and that they do not have access to services and healthcare. Villa Voortman focusses on 'welcoming' them by 'accepting them in their disparities and distinctions'. Exactly this approach offers them an opportunity to get grip on themselves during their progressive flight from society and life. Their 'bizarre' and 'a-social' behavior, as well as their substance abuse, are considered as personal answers to this exclusion and to the feelings of being reduced to objects. Indeed, if these symptoms are not seen as answers by the subject, the people risk to be dropped again, which is a recurrence of many experiences from the past. If, on the other hand, a place for this 'group of people who do not belong to a group' is created, connection is made again with the particular characteristic of psychiatry and its historical objective of providing asylum. Recognition has to be seen as a necessary precondition for treatment. In this perspective, their difficulties or issues are not the point of reference, but the structural position of those who are excluded. In concrete terms this means that Villa Voortman adapts itself to the visitor by starting the clinical practice from the question 'who are they ?' instead of 'who are we ?'. By doing so it provides clinical staff with a much better starting point not only for a therapeutic alliance, but also for helping the visitors to reclaim their position as citizens. The Villa aims to be a safe place (asylum) but at the same time the visitors are encouraged to open up 'their house' and in their turn become hosts. This is because Villa Voortman has not to be considered as an island, but rather as a part of society. It offers another perspective than that of 'normality' in which mental illness often leads to exclusion. It is a way of addressing the friction there is between the expectations of modern society and the individual needs of the visitors.

Villa Voortman aims to be a place in which 'human encounter' is made possible with respect for the individuality of each visitor. By encouraging people to take up responsibilities and by strengthening the social bond, they are re-connected with society and possibilities are created in order to join up again with treatment and care providers. This leads to a decrease in marginalization and it makes the symptoms less necessary. In order to work towards this objective, authoritarian and repressive approaches are to be avoided. Villa Voortman starts from a structure which is not obliging, binding, coercive or compelling, but rather from a structure that empowers visitors to make their own choices. Difficulties are often situated in relation to others. Therefore, it is essential to actuate this stranded communication by means 
of an adapted consultative structure within a horizontal organization in which equality, participation and consultation are central features.

The institutional psychotherapy has shown that the encounter with psychosis is a very complex matter. Treatment staff have to be aware of the risks of a dual relationship, as this can further strengthen the dissociation of persons with psychotic problems. A 'vertically structured treatment and care organisation' with clear rules creates experts, but remains stuck in the registry of the role and identity of alienation and estrangement. Only a wide scope of transference, with openness for diversity, free circulation and mobility and serendipity can preserve us from this tendency. This enables the development of a network in which exchange is fully promoted. The psychotic person will only start to act if he is left at peace, if nothing is demanded from him, if he is not addressed in a very direct way. It seems better to assume a supportive and waiting position and to focus on the environment in which he or she is trying to survive. This complex and multiple field of transference forms the basis for 'a social space of transition'(cf. Bridger (1984) cited in Broekaert et al., 2000). The following well-known principles set forth by Rapoport (1960) are used to organize the center: permissiveness, democracy, communalism and reality testing (cf. Vandevelde et al., 2004). Transparency is added to this list.

Permissiveness refers to the lack of negative consequences (censure or punishments) if visitors express emotions. Rules are kept to a minimum in Villa Voortman and state that violence and substance use are not tolerated in the centre. Problems that occur are dealt with during the community meeting. This does not mean that everything is tolerated ("laissez-faire, laissez-passer"), quite the contrary. Permissiveness works on both sides: persons can always be addressed for their behavior. The focus, however, is on giving the group the opportunity and space to recover by itself.

Democracy aims at providing equal opportunities for participation to all visitors. There is a flattened hierarchical structure and people can freely choose with whom to relate, regardless of role or function (Rapoport, 1957). Yet, inevitably, some hierarchy and power differential is nevertheless present, as this is the case in any democratic TC (Campling, 2001).

Communalism has to do with creating a climate in which people feel welcome and valued by means of installing free communication and interaction amongst all members.

Reality testing forms a counterweight for denying or minimalizing problems and escaping responsibilities. People are confronted with the image as perceived by their peers and other 
persons in Villa Voortman. The centre forms a micro-society in which all interactions of the outside world are present (Rapoport, 1956).

Transparency refers to the necessity of having an 'open system' characterized by reciprocal open communication, shared decision-making and the promotion of a therapeutic culture. Villa Voortman aims at finding the 'minimal structure' that is supportive enough to enable change in a spontaneous way. Persons begin to engage in such meaningful action as they are able to claim for themselves.

\section{Research question 2: How do the clients perceive Villa Voortman?}

The second question aimed at gaining more in-depth knowledge on the personal perspectives and experiences of the visitors of Villa Voortman and to get insight in the positive and negative factors as perceived by the visitors' themselves. A qualitative approach, involving a video method was used in this study. Visitors were asked to disclose their ideas about the question 'For what reason(s) do you come to Villa Voortman?'.

\section{Methods}

Qualitative research starts from a holistic approach, with attention to the complexity of human nature and a focus on the authenticity of human experiences (Silverman, 2009). Since this study aimed to gain insight into the personal perspectives of the visitors of Villa Voortman, a qualitative study design was set up. During the study the researcher (also third author of this paper) was involved as a trainee in the centre, which gave her the opportunity to better understand, enrich and analyse the data, based on her participatory observations. Since this position as trainee will have influenced the data gathering and analysis, the researcher frequently discussed her role, actions and observations in the visitors centre with the other authors in order to keep a reflective attitude during the whole process (Flick, 2009).

\section{Sample}

All "visitors", here used in the same way as by the Villa Voortman personnel to denote "clients" or "patients", were part of the research population of this study. Inclusion criteria for the study were being a visitor of the centre; being over 18 years old and experiencing psychological problems and a comorbid substance abuse problem (dual diagnosis). Every day between 25 and 35 individuals visit the centre. All visitors were personally invited to 
participate in the study using different channels: the study was discussed during a community meeting; there were posters announcing the study in several places of the centre; and the researcher/trainee individually spoke about the study with the visitors at several occasions the weeks before and during the research. In total, 19 visitors participated and shared their personal stories about why they were coming to the visitor centre by means of video recording equipment that was set up in a separate designated room. 4 persons ( $21 \%$ of the sample) were female and all participants were between 20 and 60 years old.

\section{Instruments}

Since the focus in this study was on the personal perceptions of the often vulnerable visitors of Villa Voortman, a low threshold and creative research method was needed. Therefore it was decided to work with video recordings. One of the rooms in the centre was transformed into a "chat room" with a camera. The use of video recordings in scientific research is a technique which is mostly used in the field of ethnography and anthropology. Video recordings are a useful method, when doing participatory scientific research, since it creates the possibility to include spontaneous information, which otherwise would not be obtained (Buchwald, Schantz-Laurens \& Delmar, 2009). Participants are free to decide how much information they are willing to share and they are less often disposed to the provision of socially desirable answers (Noyes, 2004). During a time-frame of two weeks a camera was placed in the visitors centre and during the day visitors could freely walk into the chat room to share their story. All data were registered by the camera. The research question, i.e. for what reasons a person comes to Villa Voortman, was presented on the posters as well as on an information sheet which was available in the chat room. If needed, persons could also ask more information of the researcher, which happened in some cases.

\section{Ethical considerations}

The study was set up in accordance with the ethical regulations set forth in the ethical protocol of the Faculty of Psychology and Educational Sciences at Ghent University. The data are confidentially analysed and results are anonymously reported. Information about the study, including its goals, the procedure, the confidentiality in handling the data and the way in which the data were to be reported was provided in a document that was clearly presented in the chat room, next to the webcam. As the third author, who undertook a major part in the study, was present in Villa Voortman as a trainee, questions with regard to the study could be directly addressed to her. All clients participated voluntarily. 


\section{Data analysis}

In this study an inductive approach was used, which was data-driven and did not presuppose certain themes. The only structure was the open research question: 'For what reason(s) do visitors come to Villa Voortman?'. This qualitative study starts from an interpretative phenomenological analysis, which states that a person who acquires certain experiences, is also the expert of those experiences. In other words the challenge is to capture the meaning people attach to their personal experiences in a specific context (Howitt, 2010; Smith, Larking $\&$ Flowers, 2009). This requires an intense and detailed analysis of the collected material and a constant critical reflection of the researcher.

A phenomenological analysis of the data is a creative and multidirectional process that leads to new insights on a certain theme. In order to structure this analysis, it is useful to follow a scheme to analyse the data. Therefore, the interpretation of the data consisted of six interrelated phases (Smith, Larkin \& flowers, 2009; Braun \& Clarke, 2006). Before starting to analyse the data, the collected video material was transcribed verbatim. In a first phase the transcripts were read and the video recordings were watched several times. By doing so, the researcher slowed down the process of analysis and got acquainted with the data. In a second phase the researcher noted everything of some kind of interest to answer the research question. The focus in this phase is on the descriptions and linguistic usage of the participant. In a third phase the researcher tried to reduce the volume of the details, without losing the complexity of the data. The researcher tried to reproduce the important themes from the different parts of the data in a brief and concise way. These themes will not only reflect the original thoughts of the participants, but also the interpretations of the researcher. In a fourth step the themes were ordered and connected in a tree structure. Connections were made between different themes. In a fifth step the researcher moved on with the next casus/story and went through the first four phases again. In a last phase (phase six), the most creative phase of the data analysis, the researcher looked for connections between the different stories. In this phase themes and subthemes are further labelled and configured, which resulted in a "final" tree structure. During the different phases, the researcher frequently discussed the data with two of the co-authors and the staff of the visitors centre. In order to increase the reliability of the coding process, twenty randomly selected references were independently coded by a co-researcher by use of the structured scheme. Afterwards, the researcher and the co-researcher checked whether there was consensus on the themes and also on the reason for 
consensus. In case of disagreement, the advice of a third co-researcher was sought. Data were coded in Nvivo 10, a software package that supports the content analysis of qualitative data.

\begin{tabular}{|l|l|}
\hline Themes & Subthemes \\
\hline Social inclusion & $\begin{array}{l}\text { Supportive climate } \\
\text { A second home }\end{array}$ \\
Outside Villa Voortman & $\begin{array}{l}\text { Daily support } \\
\text { Future perspectives } \\
\text { Identity }\end{array}$ \\
\hline Personal development & $\begin{array}{l}\text { Daily activity } \\
\text { Getting opportunities } \\
\text { Artistic development } \\
\text { Place to catch a breath } \\
\text { Agency }\end{array}$ \\
\hline Equality & $\begin{array}{l}\text { Connection/intimacy } \\
\text { No obligations/noncommittal } \\
\text { informal attitude }\end{array}$ \\
\hline
\end{tabular}

Table 1: Themes and sub-themes on reasons why visitors come to Villa Voortman

\section{Results}

The data revealed three main themes (social inclusion, personal development and equality) as well as several subthemes (cf. table 1).

\section{Social inclusion}

Inside Villa Voortman - belonging

One of the most prominent themes was the concept of belonging. A majority of the participants $(n=7)$ stated that they felt welcome in the visitors centre; they felt they were part of Villa Voortman, which resulted in feelings of belonging, which is linked with a supportive 
climate. This open culture has a strong impact on the perception of the visitors with regard to their relationship with the staff.

'Everyone has respect for each other. Love comes at the first place, followed by respect, affection and friendship.' (Man, 40-50 years)

Few participants $(n=3)$ described the visitors centre as their 'second home', a safe haven to return to after a long journey of other forms of treatment. The fact that the visitors centre is located in a regular house, with a cosy interior, strengthens these feelings.

'I already have a long treatment history, two residential clinics and one outpatient centre. This is something really important to me, because I feel much more comfortable here, I have the feeling I found a home here.' (Man, 30-40 years)

Two participants regretted that the centre is not open in the weekend or that there are no opportunities to live there permanently.

'Unfortunately it is not possible to live here. That would be the next step.' (Man, 30-40 years).

People with dual diagnosis are frequently confronted with social isolation. For almost a third of the participants the visitors centre functions as a counter balance for these experiences of social isolation.

'I really like to come to Villa Voortman because I found myself here again. I was getting completely isolated, and here I am surrounded by other people and I got rid of my depression as well.' (Woman, 20-30 years).

\section{Outside Villa Voortman}

By providing the visitors social, as well as practical and emotional support, the centre contributes to the integration of its visitors in society $(n=5)$. 
'They give a lot of social support, they help you with your papers, to find a house, etc. That's really important. They really underestimate those aspects in classic psychiatry. They only give attention to medication and treatment and once you're out, you end up in the same situation as before.' (Woman, 20-30 years)

A number of participants $(n=3)$ considered the centre as an opportunity to build out a new future. They saw their societal integration in a broader framework, resulting in a 'new' future.

'It's a chance for me to get a grip on my life again. It is an easy way for me to get out of prison and I will definitely use it. When I am free, I will keep coming to the centre, also when I am no longer forced to come by court.' (Woman, 30-40 years).

The visitors centre Villa Voortman tries to create a place where you have the right to be 'different'. This sub-theme is addressed here, but it is also closely connected to the theme of 'equality'. A third of the participants talked about this platform where they can be themselves, which is in contrast with often experienced forms of stigmatisation. In the centre they experience acceptance and appreciation for their qualities and possibilities, rather than focussing on mistakes they have made in their life.

Although participants had the opinion that in different treatment settings there is often too much of a focus on their 'label', a number of participants $(n=3)$ identified themselves with their 'label', as illustrated in the following citation:

'They don't mark you as a psychiatric patient or a criminal, which I am, I will not deny that. But they judge you for who you are, not for what you did wrong in your life. That warm feeling is what the centre gives to me.' (Man, 40-50 years)

\section{Personal development}

When participants talked about reasons for visiting the centre, they frequently mentioned the contribution to their personal development. Most visitors $(n=17)$ disclosed that they are looking for something to do during the day. Many of them lack a structured daily activity and the visitors centre offers daily activities such as sports, cooking, philosophy and poetry workshops, ... 
'That's what I need, some kind of structure. That's the reason why I always force myself to be here by lunch time, even when I had a bad night. By the way, the food is very cheap here, two euros.' (Man, 40-50 years).

Besides having a structured daily activity a number of participants $(n=3)$ emphasized the fact that they get opportunities in the centre to discover and to further develop their talents and competences. Furthermore, 'the artistic aspect' was very prominent in the participants' stories. The centre creates a forum for artistic development in different forms, such as music and poetry. For almost a third of the participants $(n=6)$ this was one of the main reasons to come to Villa Voortman. The artistic aspect has also a strong societal function in the centre.

'There are a lot of people who play guitar here. There is also a guitar available in the centre. So it is not only in the music workshops we can play music. We can also play guitar in the living room, while we drink a coffee and where we can smoke a cigarette.' (Man, 40-50 years).

'I am really fascinated by the artistic vibes here. It really interests me and it stimulates me to stay of the drugs.' (Man, 50-60 years)

This artistic development was also very prominent in the video recordings, where one participant recited a poem and another participant used beatbox and rap to bring his story.

A last subtheme that was cited in the video recordings in the chat room was the fact that the Villa is a place where visitors can catch a breath, physical as well as mental. More than a quarter of the participants talked about the possibility to rest in the visitors centre. The availability of a chill out room is an important aspect for persons who are homeless or who live in a squat, as it is considered as a pre-condition for further development.

'When you are tired or something, you have a chill-out room in here. When you don't feel well or your mind is messing around with you, you can just lay down for a while. (Man, 40-50 years) 
The personal stories from the visitors revealed that one of the positive factors of Villa Voortman is the fact that they work on a sense of ownership or 'agency'. The visitors centre creates the necessary time and space to develop agency, both from a personal as well as more organisational level. Every Tuesday there is a meeting, which is facilitated by the visitors themselves, where they can give their opinion about how things are organised in the centre and things that should change, amongst other topics. Moreover, the visitors have the freedom to realise their ideas, personal aspirations, art, ..., which makes the Villa 'their' place instead of merely a treatment centre.

One participant illustrated that the agency of the visitors is also used in order to assure that the two house rules (no violence and no drug use in the centre) are respected:

'This week some of the visitors arrived really stoned and then the group confronted this person with that. It is not really pleasant, if you have the urge to use drugs and you have to watch how some of the visitors are under influence of drugs. And it is much more efficient, when this comes from the group.' (Man, 30-40 years)

\section{Equality}

Different subthemes resulted in this general feeling of equality, such as being connected with other individuals/having a social network within the Villa itself. More than half of the participants $(n=11)$ mentioned the presence of other visitors, such as trainees, artists, professional staff, other individuals with a dual diagnosis as an important factor why they visit the centre. The importance of mutual conversations and the connection with other visitors (online and face-to-face) are frequently cited.

\footnotetext{
'Why I come to Villa Voortman? Well, because of the people. In reality, it are the people who make the Villa. And that's why I feel welcome here, because of the people.' (Man, 40-50 years)
}

In most psychiatric organisations there is a strong distance between staff and 'patient', while in Villa Voortman intimacy and attention for physical contact are important feelings, as is illustrated in the stories of the visitors. This space for intimacy (e.g. staff and visitors give a kiss while greeting each other) and to a certain extent also love (in both sexual (amongst 
visitors and not between staff and visitors) and non-sexual ways), results in an open and warm atmosphere. This is mainly caused by the absence of power relationships and the strong horizontal way of working in the Villa, which leads to a strong equivalence between the visitors. These feelings of equivalence contrast sharply with past experiences in residential psychiatric wards.

'What is very important for me, is that there is no gap/distance between staff and patients, as in the classic, residential psychiatry or in day care centres, to express it in psychiatric terms.' (Man, 40-50 years)

'The focus is not really on treatment and patients. It's just a bunch of people being together. And that's much more efficient. Once again, it's just more human. It's very low threshold and at the end you will learn the most from each other.' (Man, 30 -40 years)

A last subtheme raised by the participants when talking about belonging, was the fact that participation or visiting Villa Voortman is without obligations. Three participants mentioned this as a major advantage of the centre.

'I am not forced to take medication when I come here. I can talk with everyone when I want to. I am not forced to come here. That's a big difference with psychiatry, where you don't have any choice.' (Woman, 20-30 years)

Three participants had to come to the visitors centre as part of their juridical conditions, so their presence was mandated by an external organisation (in this case a court).

\section{Discussion}

The results on both research questions, resulting from the perspectives of staff and visitors, revealed some important features that characterize the particularity of Villa Voortman. These aspects include the provision of 'asylum' and shelter - a place to belong; the existence of a warm and welcoming atmosphere, in which people are accepted the way they are; the focus on real human encounter with respect for each and everyone's identity; a permissive, nonobliging, supportive and 'waiting' environment that fosters personal growth and inter- 
personal relations; a minimal but yet 'good enough' structure that stimulates participation; the importance of empowering persons to consider Villa Voortman as a place for them and by them; the necessity of a place where persons can develop themselves by means of art, music and other daily activities; the striving for social inclusion and future perspectives, with respect for one's particularities; and the support in becoming inclusive citizens again.

These results could be considered as the 'active ingredients' of the support that is offered in and by Villa Voortman. At the same time, some of these features could lead to challenges as well.

The first challenge concerns the continuous search for an equilibrium between empowering and controlling people. Whilst it is true that Villa Voortman is a very permissive environment, in which responsibility is maximally given to the visitors, it is important that staff members do take over, as the group or the individual is not able to cope with problems or difficulties. Rapoport $(1956,1960)$ describes this as oscillations in the therapeutic community, that should be taken into account. At times when "constructive" and "long-term" visitors are replaced by "new" visitors, the tension can reach a peak which demands for a reorganization of the community (Rapoport, 1956; Vandevelde \& Broekaert, 2004). In this case, treatment staff have the responsibility to intervene and restore the peace and safety. At the same time, they should consciously consider the borders of these interventions. If not, the clients' agency could be seriously compromised and limited to 'bounded empowerment' in an attempt to control the always inherent risks that come along with empowerment and emancipation (Morisse et al., 2013). Furthermore, empowerment has more connections with 'shared' than with 'own' responsibility and is, therefore, embedded in perspectives that take 'vulnerability' (and thus 'care') into account. From our point of view, striving for autonomy on the one hand and safeguarding the community safety or caring for persons by more controlling clients on the other hand is not antipodal (Bryssinck, 2013). Rather, both aspects (autonomy and control) could be considered as complementary assets that are to be used in an integrated manner, depending on the specific context and situation (Broekaert et al., 2011). In reference to the title of the paper, visitors nor treatment staff have full "carte blanche" with regard to how support develops, as this is - in our opinion - driven by the dialectal course of everything that occurs during the treatment and support process.

The second challenge refers to the future developments of Villa Voortman. Due to the positive experiences visitors have and share, the Villa is becoming more and more appealing, 
both to 'clients' as well as to professionals, trainees, students, volunteers and others. Of course, this is a good evolution, as it is exactly this mixture of people that makes Villa Voortman a real inclusive part of society. Yet, at the same time, Villa Voortman's 'popularity' may threaten the core identity of the meeting center, since the small-scale approach is undoubtedly one of its major assets. Furthermore, there is a risk that an increase in the number of clients may scare off exactly the visitors for whom Villa Voortman was set up in the first place. Exclusion by an approach set up to strive for inclusion could be the paradoxical effect of a group that is regulating itself. A future challenge, therefore, consists of searching for possibilities to safeguard the core features of Villa Voortman, by e.g. empowering visitors to take up roles in society (again) and using the Villa as a sort of temporary retreat if needed. Furthermore, existing links with society should be strengthened and further explored. This is important as the Villa can serve as part of a transitional phase, rather than as the final destination, in the process towards inclusive citizenship.

The third and fourth challenges are linked to the previous ones and concern the danger that the client group is taken over by visitors that are 'stronger' or more 'resilient' than others and the consequent impact on treatment effectiveness and efficiency. It challenges us to carefully consider how to involve and focus on the most vulnerable clients. Often, these clients are confronted with many difficulties, including the lack of a supportive social network and the fact that many of these clients have multiple disorders (Bryssinck, 2013; Drake et al., 2005). This could compromise long-lasting effects. This study has added more information to the growing knowledge base on two essential elements with regard to the evidence-based practice in supporting dually diagnosed clients. Rather than focusing solely on 'what works', we have tried to shed more light on these elements 'that make treatment work'.

This study has some limitations. First of all, due to the qualitative approach and especially because of the small number of participants, the results cannot not be generalized. Secondly, although the video method was used to set the visitors at ease, the most vulnerable persons may have been scared off by this rather impersonal contact. It may also have discouraged visitors with limited communicative skills from participating. Finally, women were underrepresented in this study, so limited attention is given to potential gender specific issues.

More research in this area is needed and the present study has indicated some promising future directions. Could the experiences in Villa Voortman be generalized to other settings and initiatives? How can society be made more accountable to take its responsibility in order 
to create a social net for these and other vulnerable persons ? Because the visitors attached great value to social inclusion, belonging and respect for their identity, to only mention a few aspects, more research on the effects of treatment and care on psychosocial indicators and quality of life is definitely needed. This complies with findings in other populations (De Mayer et al., 2009).

For the visitors of Villa Voortman, the old Heraclitus saying: "All things move and nothing remains still, and you cannot step twice into the same stream" remains vivid: A real "Carte Blanche! (or not)?

\section{References}

Braun, V. and Clarke, V. (2006), "Using thematic analysis in psychology", Qualitative Research in Psychology, Vol. 3 No. 2, pp. 77-101.

Bridger, H. (1984), "Groups in open and closed systems", in Proceedings of the First World Institute of Therapeutic Communities, 1984, Centro Italiano di Solidarieta, Rome, pp. 54-70.

Broekaert, E., Vanderplasschen, W., Temmerman, I., Ottenberg, D.J. and Kaplan, C. (2000), "Retrospective study of similarities and relations between American drug-free and European therapeutic communities for children and adults", Journal of Psychoactive Drugs, Vol. 32 No. 4, pp. 407-417.

Broekaert, E., Vandevelde, S., Soyez, V., Yates, R. and Slater, A. (2006), "The third generation of therapeutic communities: The early development of the TC for addictions in Europe", European Addiction Research, Vol. 12 No. 1, pp. 1-11.

Broekaert, E., Vandevelde, S. and Briggs, D. (2011), “The postmodern application of holistic education", Therapeutic Communities, Vol. 32 No. 1, pp. 18-34.

Bryssinck, D. (2013), “Bemoeizorg tussen ethiek en pragmatiek”, in Van Kerckhove, C., De Kock, C. and Vens, A. (Eds.), Ethiek en zorg in de hulpverlening, Academia Press, Gent, pp. 71-89.

Bryssinck, D., Broekaert, E. and Vandevelde, S. (2005), "Psychosis and newly emerging dependency groups: The search for an adapted model of care at the Psychiatric Centres Sleidinge in Belgium”, Therapeutic Communities, Vol. 26 No. 2, pp. 150-162. 
Buchwald, D., Schanz-Laursen, B. and Delmar, C. (2009), "Video Diary Data Collection in Research with Children: An Alternative Method", International Journal of Qualitative Methods, Vol. 8 No. 1, pp. 12-20.

Campling, P. (2001). Therapeutic communities. Advances in Psychiatric Treatment, Vol. 7, pp. 365-372.

Crossley, N. (1998), "R.D. Laing and the British anti-psychiatry movement: a socio-historical analysis”, Social Science and Medicine, Vol. 47 No. 7, pp. 877-889.

Davidson, L., Mezzina, R., Rowe, M. and Thompson, K. (2010). "A life in the community: Italian mental health reform and recovery", Journal of Mental Health, Vol. 19 No. 5, pp. 436443.

De Leon, G. (2000), The therapeutic community. Theory, model and method, Springer, New York.

De Maeyer, J., Vanderplasschen, W. and Broekaert, E. (2009), "Exploratory Study on Drug Users' Perspectives on Quality of Life: More than Health-Related Quality of Life?”, Social Indicators Research, Vol. 90 No. 1, pp. 107-126.

Drake, R. E., Wallach, M. A., and McGovern, M. P. (2005), "Future directions in preventing relapse to substance abuse among clients with severe mental illnesses", Psychiatric Services, Vol. 56 No. 10, pp. 1297-1302.

Flick, U. (2009), An Introduction to Qualitative Research, London, Sage.

Foucault, M. (1965), Madness and civilization: A history of insanity in the age of reason, Pantheon / Vintage Books, New York.

Friedman, M. (1976), “Aiming at the self: The paradox of encounter and the human potential movement", Journal of Humanistic Psychology, Vol. 16 No. 2, pp. 5-34.

Goffman, E. (1961), Asylums. Essays on the Social Situation of Mental patients and Other Inmates, Penguin, Harmondsworth.

Harrison, T. and Clark, D. (1992), "The Northfield Experiments", British Journal of Psychiatry, Vol. 160 No. 5, pp. 698-708. 
Hayes, S. (2013), “Archive visit at the Planned Environment Therapy Trust $-27^{\text {th }}$ February 2013" available at http://www.pettrust.org.uk/archive-news/blog/page-3 (accessed 6 December 2013).

Hinshelwood, R.D. (1991), "Psychoanalytic influences upon the therapeutic community", International Journal of Therapeutic Communities, Vol. 12 No. 2-3, pp. 109-115.

Howitt, D. (2010), Introduction to Qualitative Methods in Psychology, Pearson Education Limited, Essex.

Jones, M. (1968), Beyond the therapeutic community: Social learning and social psychiatry, Yale University Press, London.

Jones, M. (1984), "The two therapeutic communities. A review", in Proceedings of the eighth World Conference of Therapeutic Communities, 1984, Centro Italiano di Solidarieta, Rome, pp. 29-35.

Kennard, D. (1998), An introduction to therapeutic communities, Jessica Kingsley Publishers, London.

Lister, R. (2007), "Inclusive citizenship: realizing the potential”, Citizenship Studies, Vol. 11, No. 1, pp. 49-61.

Morisse, F., Vandemaele, E., Claes, C., Claes, L and Vandevelde, S. (2013), "Quality of Life in persons with intellectual disabilities and mental health problems: An explorative study", The Scientific World Journal, doi: 101155/491918.

Noyes, A. (2004), "Video diary: a method for exploring learning dispositions", Cambridge Journal of Education, Vol. 34 No. 2, pp. 193-209.

Perron, A., Trudge, T., and Holmes, D. (2010), "Citizen minds, citizen bodies: the citizenship experience and the government of mentally ill persons"; Nursing Philosophy, Vol. 11 No. 2, pp. 100-111.

Rapoport, R. N. (1956), “Oscillations and sociotherapy”, Human Relations, Vol. 9 No. 3, pp. 357-374.

Rapoport, R.N. and Rapoport, R.S. (1957), “'Democratization’ and authority in a therapeutic community", Behavioral Science, Vol. 2 No. 2, pp. 128-133. 
Rapoport, R.N. (1960), Community as doctor. New perspectives on a therapeutic community, Tavistock Publications, London.

Silverman, D. (2010), Doing Qualitative Research (Third Edition), Sage, London.

Smith, J.A., Larkin, M. and Flowers, P. (2009), Interpretative Phenomenological Analysis: Theory, method and research: understanding method and application, Sage, London.

Vandevelde, S. and Broekaert, E. (2009), A pioneer of milieu therapy: The life and work of Maxwell Jones, Garant, Antwerpen, Apeldoorn.

Vandevelde, S., Broekaert, E., Yates, R. and Kooyman, M. (2004), "The development of the therapeutic community in corrections: a comparative retrospective account on the 'democratic' Maxwell Jones TC and the 'hierarchical' concept-based TC', International Journal of Social Psychiatry, Vol. 50, No. 1, pp. 66-79.

Ware, N.C., Hopper, K., Tugenberg, T., Dickey, B. and Fischer D. (2007), “Connectedness and citizenship: redefining social integration”, Psychiatric Services, Vol. 58 No. 4, pp. 469474. 